\title{
A Preliminary Study on Gum Arabic as a Binder in Preparation of Starch Based Edible Plastic
}

\author{
N. Ayuni A. Apandi, N. A.Salfarina A. Razak, Mustika Masri, S.F. Yusoff \& Azwan Mat Lazim \\ School of Chemical Sciences \& Food Technology, Faculty of Science \& Technology, Universiti Kebangsaan Malaysia, \\ 43600 Bangi, Malaysia \\ E-mail:azwani79@ukm.my
}

\begin{abstract}
This research emphasizes on synthesizing edible plastic using a one pot method by adding starch, gum Arabic as the binder and sugar (sorbitol and glycerol). In order to get the right composition, the ratio of each ingredient was varied. The FTIR spectroscopy was used to characterize the structure and composition of the sample produced.
\end{abstract}

Keywords — Edible Plastic; Starch; Sorbitol; Glycerol.

\section{INTRODUCTION}

Gum arabic has been widely used in food industry because of its high water solubility, low solution viscosity and low interfacial activity. These properties made gum arabic very useful in many applications especially in the food industry. For example, it widely used as flavor encapsulator and also stabilizer of citrus emulsion in soft drinks [1]. Furthermore, gum arabic is the best emulsifier in oil-in-water emulsion systems which very important in pharmaceutical industries $[1,2]$.

As far as our concerned, there was no literature discussed on the utilization of gum Arabic as a binder for making edible plastic. Therefore, the aim of this work is to carry out a preliminary study on the preparation of edible plastic by using potato starch with the additional of gum arabic, glycerol, and sorbitol at different ratios. The temperature is varied between $40{ }^{\circ} \mathrm{C}$ to $70{ }^{\circ} \mathrm{C}$. The samples were analyzed by Fourier Transform Infrared spectroscopy (FTIR).

\section{METHODOLOGY}

In a beaker, gum Arabic was dissolved with distilled water and heated for 60 minutes at $40{ }^{\circ} \mathrm{C}$ and labeled as sample A. Meanwhile, potato starch, glycerol and sorbitol was mixed with different ratio and labeled as sample B. Both samples were mixed together, stirred and heated for 30 minutes at $70{ }^{\circ} \mathrm{C}$. The mixture was then placed in a petri dish and left in the oven for 24 hours at $50{ }^{\circ} \mathrm{C}$.

\section{RESULT AND DISCUSSION}

\section{A. Edible plastic texture}

The experiment showed that the best ratio to prepare a good edible plastic was 20:20:10 wt\% (gum Arabic: starch : glucose). Further experiment was made to determine the best ratio of glucose by adjusting the sorbitol and glycerol. As reported previously, the sorbitol was able to act as plasticizer, where it gave the hardness and made it less flexible. Whereas, the glycerol gave softness to the plastic structure. It was found $0.1 \mathrm{wt} \%$ of sorbitol and $0.2 \mathrm{wt} \%$ of glycerol gave the best texture of the edible plastic. A transparent plastic was obtained without sticky or brittle. This texture is important the food coating purposes (Fig. 1)

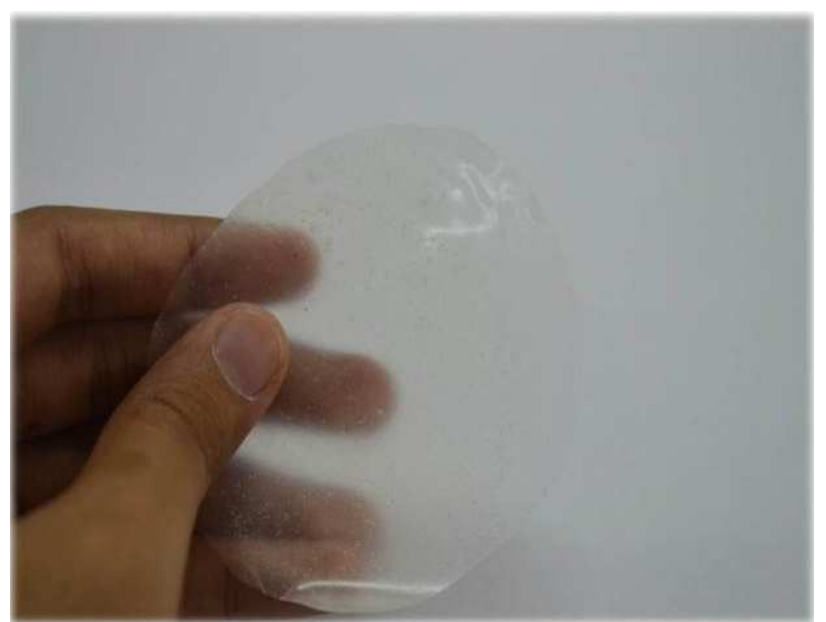

Fig. 1: A transparent edible plastic with a ratio of 20:20:10 wt\% (gum Arabic: starch: glucose) 
It was also found that the amount of gum Arabic used was also important for edible plastic preparation. Only $0.1 \mathrm{~g}$ was needed, otherwise the plastic texture became jelly-like with less gum Arabic while the product unpeel-able if the amount of gum Arabic excessed (Figure 2).

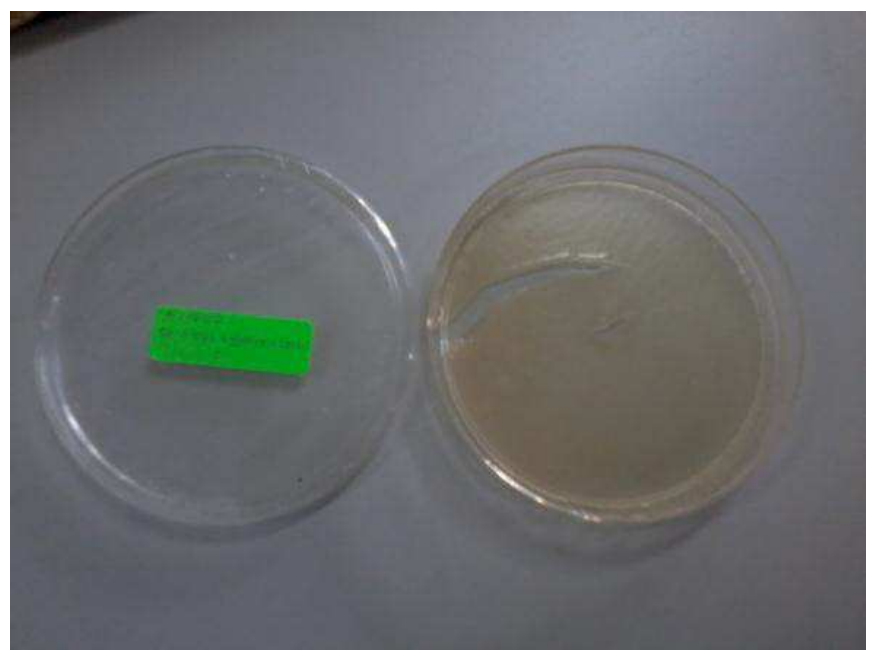

Fig. 2: Starch based edible plastic with excess gum Arabic

The heating and drying process was important due to the starch was sensitive to any temperature changes. If sample was heated over $50{ }^{\circ} \mathrm{C}$ caused the plastic burned and the color turned to be brownish. Also, the edge of the plastic became hard and brittle (Fig. 3)

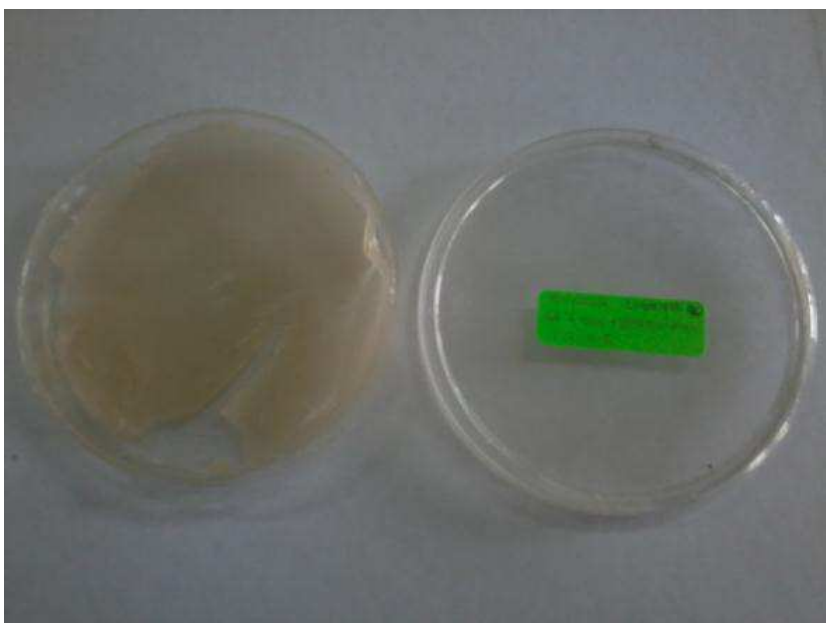

Fig. 3 Brittle and hard sample of edible plastic sample at overheated temperature

\section{B. FTIR analysis}

Figure 4 shows an infrared spectrum control sample which contains gum Arabic, glycerol and sorbitol. A typical stretching of hydroxyl $(\mathrm{OH})$, the double bond $(\mathrm{C}=\mathrm{C})$ and carbonyl $(\mathrm{C}=\mathrm{O})$ group at $3321 \mathrm{~cm}-1,1637 \mathrm{~cm}-1 \mathrm{~cm}-1$ and $1040 \mathrm{~cm}-1$ respectively. A broad peak is observed at 3321 $\mathrm{cm}-1$ due to unreacted alcohol solvent. The peak at $1040 \mathrm{~cm}-$ 1 represents (C-O) primary, secondary or tertiary alcohol [35]
A similar trend of spectrum can be seen for the edible plastic sample (Figure 5). The broadband of $\mathrm{OH}(3282 \mathrm{~cm}-1)$ is contributed by the glycerol and sorbitol that being used in the sample. Three significant peaks 2928, 1638, and 1338 $\mathrm{cm}-1$ demonstrates the stretching of $\mathrm{C}-\mathrm{H}$ bond $[6,7]$.

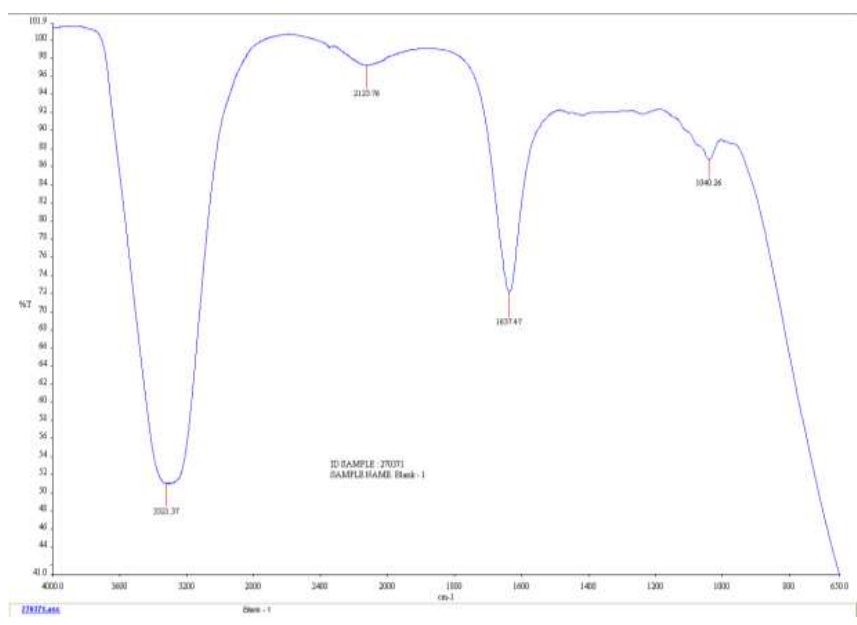

Fig. 4 FTIR spectroscopy for a control sample

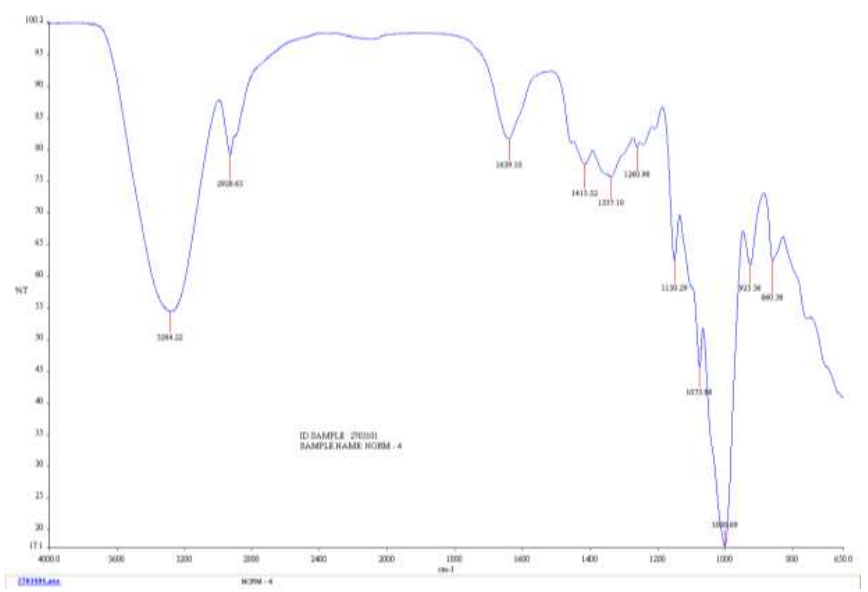

Fig 5. FTIR spectroscopy for edible plastic sample

\section{CONCLUSIONS}

Starch based edible plastic was successfully prepared by using a mixture of starch, gum Arabic and glucose. The experiment showed that the best ratio to prepare a good edible plastic was 20:20:10 wt\% (gum Arabic: starch: glucose). It was found $0.1 \mathrm{wt} \%$ of sorbitol and $0.2 \mathrm{wt} \%$ of glycerol and $0.1 \mathrm{~g}$ gum Arabic with a temperature of $50{ }^{\circ} \mathrm{C}$ gave the best texture of the edible plastic, Fourier Transform Infrared spectroscopy (FTIR) was used to determine the functional groups of the edible plastic.

\section{ACKNOWLEDGMENT}

The authors would like to thank the Ministry of Higher Education (MOHE) and Universiti kebangsaan Malaysia (UKM) for supporting this work by a research grant FRGS/1/2011/SG/UKM/02/25 


\section{REFERENCES}

[1] Asgar Ali, Mehdi Maqbool, Senthil Ramachandran, Peter G. Alderson. Gum Arabic As A Novel Edible Coating For Enhancing Shelf-Life And Improving Postharvest Quality Of Tomato(Solanum Lycopersicum L.) Fruit. Journal Of Postharvest Biology And Technology $58:$ 42-47.2010

[2] Hyun Jin Park. Development Of Advanced Edible Coatings For Fruits. Journal Of Food Science And Technology 10 : 254-260. 1999.

[3] J. Prakash Maran, V. Sivakumar, R. Sridhar, V. Prince Immanuel. Development Of Model For Mechanical Properties Of Tapioca Starch Based Edible Films. Journal Of Industrial Crops And Products 42 : 159-168. 2012.

[4] Lucia Fama, Ana M. Rojas, Silvia Goyanes, Lia Gerschenson. Mechanical Properties Of Tapioca-Starch Edible Films Containing Sorbates. Journal Of Food Science And Technology 38 : 631-639. 2004.

[5] Maria V. Tzoumaki, Costas G Biliaderis, Miltiadis Vasilakakis. Impact Of Edible Coatings And Packaging On Quality Of White Asparagus (Asparagus Officinalis, L) During Cold Storage. Journal Of Food Chemistry $117: 55-63.2009$.

[6] Robson Maia Geraldine, Nilda De Fatima Ferreira Soares, Diego Alvarenga Botrel, Leticia De Almeida Goncalves. Characterization And Effect Of Edible Coatings On Minimally Processed Garlic Quality. Journal Of Carbohydrate Polymers 72 : 403-409.2007.

[7] S. Chillo, S . Flores, M. Mastromatteo, A. Conte, Lia Gerschenson, M.A. Del Nobile.Influence Of Glycerol And Chitosan On Tapioca Starch-Based Edible Film Properties. Journal Of Food Engineering $88: 159-168.2008$. 